\title{
COVID-19 AND UNEMPLOYMENT: EVIDENCE FROM PUERTO RICO USING BAYESIAN ANALYSES WITH HIGH- FREQUENCY DATA
}

\author{
Wilfredo TOLEDO \\ Econometrics and Stat Research, San Juan, Puerto Rico \\ Corresponding author's e-mail: wilfredotoledo@aol.com
}

\begin{abstract}
The paper aims at determining the relationship between the Covid-19 contagion level and the state of the economy using high-frequency data from Puerto Rico. In order to achieve the aim set, the direction of the causality relationship between the numbers of infected persons and the unemployment rate was determined. Furthermore, various Bayesian statistical models were estimated. The analysis results imply that the unemployment rate responds moderately to the Covid-19 contagion level itself and not the other way around. The $95 \%$ credible interval for the elasticity coefficient of the unemployment rate relative to the virus is estimated as [0.0140-0.1448]. Evidence also shows that at the beginning of 2021, most of the fluctuations in the unemployment rate were explained directly by the Covid-19 perturbations. Hence, no evidence was found that economic activity promoted the virus spread in the analysed economy.
\end{abstract}

Keywords: Bayesian Estimation, Covid-19, Economic Activity, MIDAS Estimation, Puerto Rico.

JEL Classification: C11, C22, E24, I12

\section{INTRODUCTION}

The coronavirus disease (Covid-19) has been affecting the whole world since the beginning of 2020 (ILO \& OECD, 2020). In response, most countries have implemented policy interventions, such as the closure of schools and universities and national lockdowns. These limitations on normal activities have led to economic disruptions that are more significant than those observed in regular business cycles. There are several ways in which these restrictions can affect the labour market, including a decrease in aggregate demand and an increase in production costs. This paper investigates the effects of the Covid-19 outbreak on Puerto Rico's unemployment by employing high-frequency (daily and weekly) data covering the period of 2020-2021.

The specific aim of this article is to analyse the interaction between the Covid19 contagion level and economic activity. Thus, the role of economic activity in promoting the infection and the effect of the virus contagiousness on the economy is examined. A Bayesian Vector Autoregression (BVAR) system is utilised to examine these two topics. It is important to recall that this virus affects the economy at a daily and weekly frequency. However, there are few economic indicators of 
data available at this high frequency. Therefore, in the present paper, the insured unemployment rate, available weekly, is used as the indicator of economic activity.

The use of high-frequency data allows estimating the models because the period analysed is short. If the economic agents make their decisions daily or weekly as information about the effects of the virus arises in this regularity, using lower frequency data could lead to flawed inferences in VAR models, as Christiano and Eichenbaum (1986) point out. Thus, these are some advantages of using highfrequency data for the analysis.

\section{LITERATURE REVIEW}

This paper is related to the rapidly expanding literature about the economic effects of the Covid-19 virus. One shortcoming that has confronted this research line is the lack of sufficient observations for confirmatory statistical analyses. Thus, the aspects of the topic examined have been determined in part by data availability. Various studies use the daily stock market series to evaluate some economic consequences of this virus. For example, Baker et al. (2020), Topcu and Gulal (2020), Gormsen and Koijen (2020), Onyele and Nwadike (2020), and Haroon and Rizvi (2020) find an adverse impact of the pandemic on the return or the volatility of stock markets indices. On the other hand, Lewis et al. (2020) propose a weekly economic index (WEI) to track the dynamics of the economic activity associated with the Covid-19 virus in the United States. The authors evaluated this economic indicator and stated that it was a valuable tool for assessing the economic effects of this illness.

Other studies used General Equilibrium Models or data from other pandemics that occurred in the past to assess the impact of the virus on the economy. Jorda, Singh, and Taylor (2020) study the macroeconomic responses to historic pandemic events. Their analysis covering the years from 1314 to 2018 concludes that the pandemics of the last millennium have been associated with subsequent low returns on assets. For its part, Eichenbaum, Rebelo, and Trabandt (2020) extend an epidemiology model to study the interaction between economic activity and pandemics. In that model, the virus generates both supply and demand shocks that affect the economy. Eichenbaum et al. (2020) conclude that there is a trade-off between the short-run recession caused by the pandemic and its health consequences. Thus, the governmental policies must balance the effects on these two somewhat conflicting objectives.

To examine the impact of the virus on the labour market, Bauer and Weber (2020) use the inflow of workers from employment to unemployment by regions (16 federal states) and industries (2-digit level industry classification) in Germany. Using a difference-in-difference estimation, they report that $60 \%$ of the increase in inflows from employment into unemployment in April 2020 can be explained by the shutdown measures. In the same line, Yu, Xiao Li, Y. (2020) study the impact of the Covid-19 pandemic on the labour force participation rate from a crosscountry analysis (134 countries from 1970 to 2015). They find evidence that the pandemic modifies human behaviour and reduces the labour force participation rate (LPR). According to the authors, this adverse impact could be the result of cultural 
attitudes toward uncertainty. Thus, they state that those countries with a higher uncertainty avoidance index show a more significant fall in the LPR. Another interesting study is that by Alfanza (2021); it analyses the effect of increased telecommuting agreements due to the COVID-19 pandemic on employees' productivity and work-life balance. The author's analysis uses a sample of 396 companies with telecommuting employees in the Philippines. The author concludes that the shift to remote work does not affect employees' productivity adversely. However, Alfanza (2021) shows evidence that this type of work has a significant negative impact on employees' work-life balance.

For the case of the United States, Falk et al. (2021) examine the trends of the unemployment rates, labour force participation rates, and nonfarm payrolls during the Covid-19 pandemic. The analysis shows that the unemployment rate in April 2020 was $14.8 \%$, which was the maximum value for this variable since 1948 . The authors also observe that the labour force participation rate declined to $60.2 \%$ in that month, a record low since the 1970s. Further, they report that from January 2020 to April 2020, the nonfarm payrolls dropped to $86 \%$ of their insured unemployment rate pre-pandemic level. Relatedly, Coibion, Gorodnichenko, and Weber (2020) used a survey of the country's households to determine the impact of the Covid-19 pandemic on labour markets. Their results show that job loss has been significantly larger than the number implied by new unemployment claims and that many of those who had lost their jobs did not search for new ones. They also estimate that the labuor participation rate dropped by seven percentage points. According to the authors, early retirement almost entirely explains the drop in labour force participation.

An analysis for the Euro area labour market using a sign-restricted vector autoregressive model was presented by Anderton et al. (2020). They examined the effect of Covid-19 and the associated control measures on total hours worked in this region. The authors report that both labour supply and aggregate demand shocks may explain the reduction in this variable. The authors also affirm that the decrease in working hours is the consequence of lockdown impact and the decline in the labour force due to discouragement on the part of workers regarding the pandemic. Shobande and Ogbeifun (2020) shed some light on this issue by using a panel dataset of 79 countries and estimating that the spatial COVID-19 spread has raised the mortality attributed to the virus. They also find that social stress contributes to mortality from the incidence of COVID-19. Thus, individuals' concern regarding participating in the labour market under these circumstances may be related to the assessment they make about the virus health consequences.

Finally, the International Labour Organisation, in conjunction with the Organisation for Economic Cooperation and Development, (2020) analyses the economic impact of the COVID-19 pandemic on the G20 countries. The study shows that the effects of the pandemic and containment measures led to a severe contraction in economic activity. According to the research, industrial production declined by around $28 \%$ between February and April 2020 in the examined countries. Nevertheless, government assistance alleviated the effect of the pandemic on the labour market. Thus, although the unemployment rate increased 
considerably in some countries, like Canada and the United States, it was less than what would have been anticipated given the reductions in employment.

\section{THEORETICAL AND EMPIRICAL CONSIDERATIONS}

The Covid-19 pandemic has no precedent. Its effects present some challenges to policymakers worldwide because they must consider the impact of the virus on public health and its consequences and those of policies on economic activity. Figure 1 shows a simple scheme of these relationships. The authorities must examine the level of Covid-19 and the state of the economy to determine the policy actions. On the other hand, the infection affects economic activity because of the illness of employees (fewer hours of work) and a decrease in consumers' demands. Finally, high levels of economic activity imply more interactions among individuals and may increase the contagion rate.

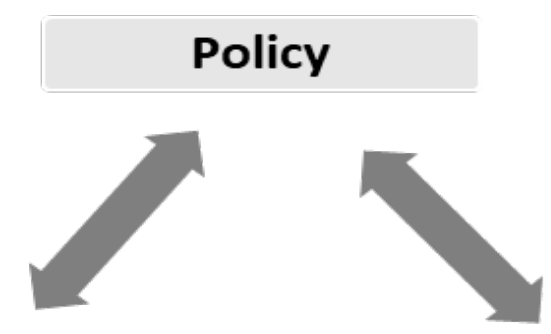

\section{Covid-19 Transmission Levels}

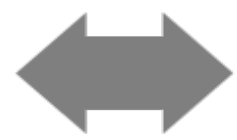

Economic Activity

Fig. 1. Relationships between government policies, economy and health.

The policymaker may minimise a social welfare loss function given by:

$$
L W=\alpha_{1}(C R-\overline{C R})^{2}+\alpha_{2}(S E-\overline{S E})^{2},
$$

where LW is the loss in welfare that the society experiences as the choice variables deviate from their targets (variables with the bar). $\mathrm{CC}$ is the virus contagion indicator used to assess the level of transmission; SE is the state of the economy determined by some economic indicators; and $\alpha_{i}$ are the weights that measure the importance that authorities give to each of the two objectives.

The potential policies include curfews for citizens and limitations for business operations. Furthermore, the government can make transfer payments for individuals and firms to lessen some of the adverse economic effects of the restrictive measures. In this setting, the policy actions can result from the anticipation of the virus consequences and may not necessarily be based upon the actual transmission rate. Thus, there is a high probability of a strong reaction to Covid-19, even with low infection levels.

In this paper, the daily number of people infected by the virus was used as CC, and the insured unemployment rate (UR), the number of individuals getting 
unemployment benefits divided by the size of the labour force, is used as the economic indicator. This last choice has several advantages. First, it is available on weekly frequency. Second, the Covid spread rate and the policies to deal with the pandemic affect this indicator, mainly in the same direction. Illness may send patients into unemployment for some weeks. Moreover, the government may restrict economic activity and increase UR. The rise in the unemployment benefits (pandemic unemployment assistance (PUA) in the U.S., for example) also may raise the unemployment rate of low-paid workers. Thus, using the unemployment rate as an economic indicator, it is possible to better estimate all the impact of the Covid contagion rate, directly and through the emergency policy actions, because they move this variable in the same direction. Consequently, its effects do not cancel out.

\section{METHODOLOGY}

A Bayesian Vector Autoregressive (BVAR) model was the principal technique utilised for the analysis of the topic under research. The system can be expressed in the following way:

$$
\left[\begin{array}{l}
U R_{t} \\
C C_{t}
\end{array}\right]=\left[\begin{array}{ll}
\phi_{11}(L) & \phi_{12}(L) \\
\phi_{21}(L) & \phi_{22}(L)
\end{array}\right]\left[\begin{array}{l}
U R_{t} \\
C C_{t}
\end{array}\right]+\left[\begin{array}{l}
\varepsilon_{U R} \\
\varepsilon_{C C}
\end{array}\right]
$$

where UR represents the insured unemployment rate ${ }^{1}, \mathrm{CC}-$ the total number of people infected with Covid-19, $\varepsilon_{U R}$, and $\varepsilon_{C C}$ is the stochastic processes that affect UR and CC, and $\phi(L)$ is a polynomial in the lag operator that contains the coefficients associated with the right-side variables of the system.

For the Bayesian analysis, it is necessary to specify the prior probability distribution of the $\phi s$ and variance-covariance matrix $\left(\sum\right)$ of the model. In BVAR models, the parameters are considered random variables. The idea is to represent the known information for all the variables through a prior distribution and combine them with the objective data coming from observations to obtain the posterior distribution. The application of Bayes' theorem commonly derives the posterior distributions. In this paper, the Minnesota prior developed by Litterman (1980) ${ }^{2}$ was used. This prior is based on the assumption that $\sum$ is known. This matrix is replaced by its estimate in a preliminary unrestricted VAR. Hence, it is necessary only to establish the prior for the parameters $(\phi s)$. The prior distribution of them, as presented by Litterman, is represented as follows:

$$
\phi_{i j}^{\ell} \sim N\left(\phi_{i j, 0}^{\ell}, \Psi_{0}\right)
$$

where $\phi_{i j}^{\ell}$ is the coefficient on lag $\ell$ of variable $j$ in equation $i$, and $\Psi_{0}$ is the variance-covariance matrix of the $\phi_{i j}^{\ell}$.

\footnotetext{
${ }^{1}$ The insured unemployment rate is the number of persons receiving unemployment insurance divided by the labour force. This variable was used because it is available at a weekly frequency. ${ }^{2}$ See also Doan, Litterman and Sims (1984).
} 
The Minnesota prior considers that each variable of the system behaves like a random walk process. Therefore, $E\left[\phi_{i j}^{\ell}\right]=1$, for $\ell=1$ and $i=j$, zero otherwise. The uncertainty around this prior is determined by the parameter variances (or standard deviation). Litterman proposes a diagonal variance matrix with the elements given by:

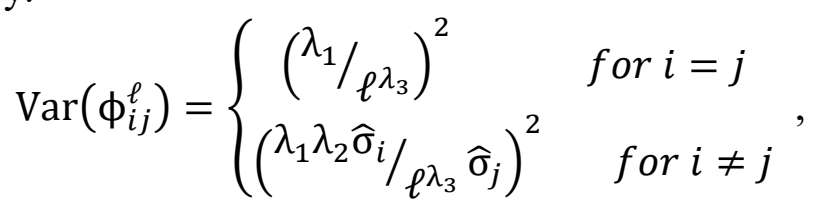

where $\operatorname{Var}\left(\phi_{i j}^{\ell}\right)$ is the variance of the coefficient on lag $\ell$ of variable $j$ in equation $i$ and $\widehat{\sigma}_{i}$ is the standard error of the residuals in the $i^{\text {th }}$ equation in the unrestricted VAR model. These variances depend upon three scalars, $\lambda_{1}, \lambda_{2}$ and $\lambda_{3}$, that are chosen to simplify the elements of $\operatorname{Var}\left(\phi_{i j}^{\ell}\right)$. Here, $\lambda_{1}$ controls the overall tightness, $\lambda_{2}$ controls the tightness of the prior lags of the cross-variable lag coefficients, and $\lambda_{3}$ determines the decay of the lags. Usually, the values of the parameters are set as $\lambda_{1}=0.2, \lambda_{2}=1$, and $\lambda_{3}=1$ or $\lambda_{3}=2$. The variance of the exogenous variables is set to infinity (no prior information about it).

\section{THE DATA}

As mentioned above, the estimation was performed using data from Puerto Rico. The weekly data for the insured unemployment rate (UR) come from the U.S. Bureau of Labour Statistics (n.a.). The number of people infected each day with the Covid-19 virus comes from the Puerto Rico Department of Health. The principal estimation was done using weekly data, and the Covid virus series was transformed using its average. The data comprise the period from 3 July 2020 to 4 October 2021.

Table 1 shows the descriptive statistics of the variables under analysis.

Table 1. Descriptive Statistics of the Series (Weekly Data)

\begin{tabular}{|l|c|c|c|}
\hline \multirow{2}{*}{ Statistic } & Number of Covid-19 Infections & \multicolumn{2}{c|}{ Unemployment Rate (\%) } \\
\cline { 2 - 4 } & $\begin{array}{c}\text { March 2020 } \\
\text { April 2021 }\end{array}$ & $\begin{array}{c}\text { March 2020 } \\
\text { April 2021 }\end{array}$ & $\begin{array}{c}\text { January 2019 } \\
\text { December 2019 }\end{array}$ \\
\hline Mean & 1917.328 & 11.074 & 1.967 \\
\hline Median & 1638.000 & 7.5700 & 1.980 \\
\hline Maximum & 5835.000 & 26.750 & 2.490 \\
\hline Minimum & 11.000 & 1.7900 & 1.570 \\
\hline Std. Dev. & 1655.643 & 7.677 & 0.219 \\
\hline Skewness & 0.765 & 0.586 & 0.454 \\
\hline Kurtosis & 2.736 & 1.896 & 3.081 \\
\hline Jarque-Bera (JB) & 5.822 & 6.265 & 1.839 \\
\hline$P$-Value of JB & 0.054 & 0.044 & 0.399 \\
\hline Observations & 58 & 58 & 53 \\
\hline
\end{tabular}

Source: The author's calculations 
The weekly average of individuals infected with Covid-19 was around 1917, and the median was 1638 from March 2020 to April 2021. This variable fluctuated from 11 to 5835 cases in this period. On the other hand, UR had a mean of $11 \%$, with a maximum value of $26.7 \%$ and a minimum of $1.8 \%$ from 2020 to 2021 . It can be observed in Table 1 that in 2019, the weekly average unemployment rate was 1.97, and it fluctuated between 1.6 and 2.5. Thus, there was a significant increase in this economic indicator when the Covid-19 virus arose. In the estimation period, the two variables under analysis experienced large variations that could be modelled with the econometric techniques.

The skewness and kurtosis coefficients for the COVID-19 variable are 0.765 and 2.736, respectively. This indicates a moderately skewed and light-tailed distribution for this variable. Nonetheless, the hypothesis that the virus indicator comes from a normal distribution cannot be rejected at the 0.01 or 0.05 significance level, judging by the P-value of the Jarque-Bera statistic. On the other hand, for the unemployment rate, the measures of skewness and kurtosis do not depart considerably from the normal distribution values for the data of 2019. However, for the period under analysis, March 2020 to April 2021, the skewness statistic assumes the value of 0.586 , while kurtosis is measured as 1.896 . This implies that the distribution of UR for this period is more skewed and has a thinner tail (less outliers) than the Gaussian. When both measures are combined in the Jarque-Bera statistics, a $P$-value of 0.044 is computed; thus, the normality hypothesis cannot be rejected at a significance level of 0.01 but is rejected at the 0.05 level.

Figure 2 shows the dynamics of the growth rate of both variables during the period utilised for the analysis. The general trend of UR and the Covid-19 variable look similar, though there is not a perfect movement synchronization.

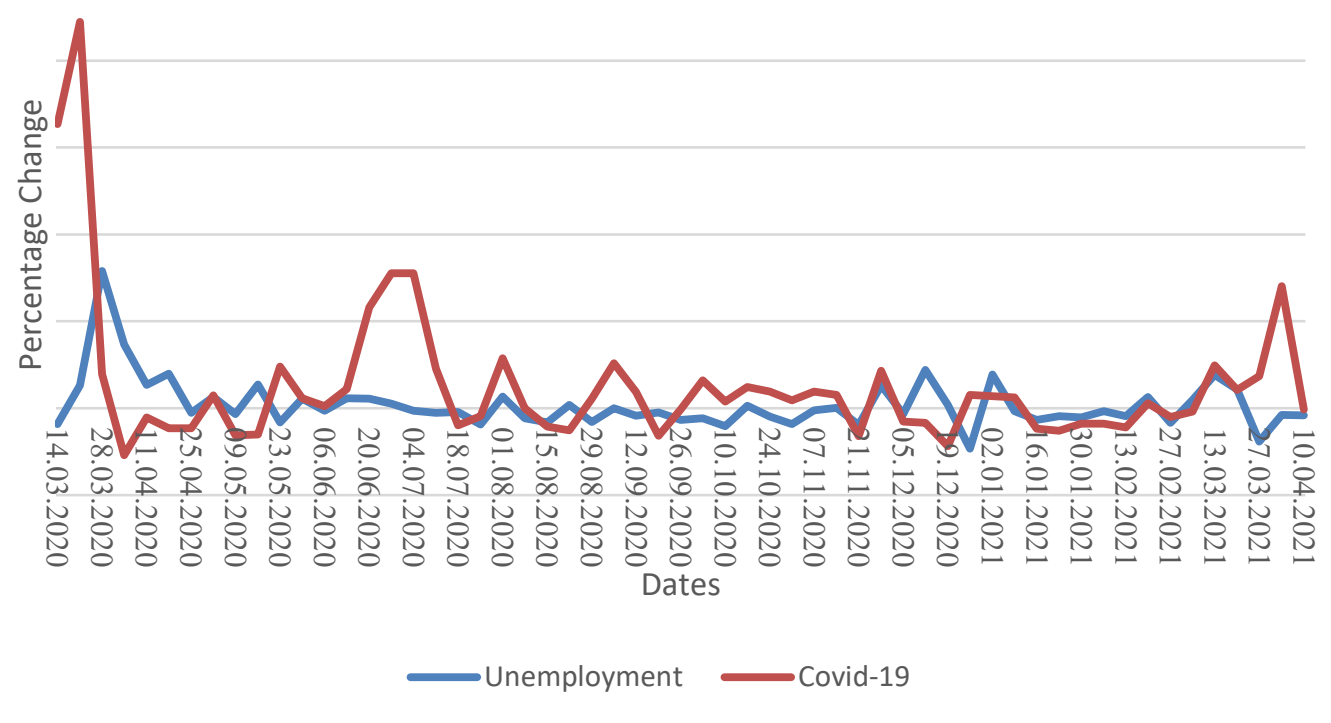

Fig. 2. Percentage change of the unemployment rate and the number of persons infected with Covid-19. 


\section{BAYESIAN VAR ESTIMATION RESULTS}

For exploratory analysis, an unrestricted VAR model was estimated. The system was specified according to the levels of the variables, with two lags of the endogenous variables determined by the Akaike information criteria. The model includes a linear trend variable and a dummy variable that assumes the value of one if a 24-hour lockdown (curfew) is in effect and zero if not. Weekly data were used for this estimation. The roots of the characteristic polynomial of the system imply that the system is stable (all less than one). Furthermore, using this system specification, a Granger causality test suggests that the Covid-19 contagion level causes the unemployment rate. ${ }^{3}$ It means that the human interactions associated with the economic activities were not the main reason for the diffusion of the viral infections in the country under analysis. Thus, in further analyses, this preliminary result is evaluated.

The Bayesian VAR model was estimated using the specifications described in the preceding paragraph. The Minnesota prior (Litterman, 1980) was utilised in this estimation. For this procedure, 50000 draws were generated, and 10000 were used in the burn-in process.

The impulse-response functions were used to evaluate the impact of the system shocks on the unemployment rate trajectory. As shown in Fig. 3, the unemployment rate increases in response to its own shocks and the Covid-19 contagion level perturbations. Both types of impulses increase the unemployment rate, but the Covid shocks have a higher effect. UR innovations have their greatest impact on the initial period and die down rapidly. In contrast, the maximum effects of the virus impulses on unemployment occur after six periods. The response of UR to the unexpected increases in the infection exhibits high persistence. Thus, the impulseresponse function results indicate that fluctuations in the virus are transmitted to the unemployment rate. On the other hand, the impact of the unemployment rate on the Covid-19 transmission level is negligible, as shown in Fig. 4. Hence, there is no evidence that an increase in economic activity adversely affected the virus dissemination level. This finding coincides with the aforementioned Granger causality test.

\footnotetext{
${ }^{3}$ The $P$-value for the $F$-statistic associated with the hypothesis that UR does not Granger-cause Covid was 0.22 . Thus, this hypothesis cannot be rejected. However, the $P$-value of the $F$-statistic for the hypothesis that Covid does not Granger-cause UR was 0.04 , and this hypothesis may be rejected.
} 


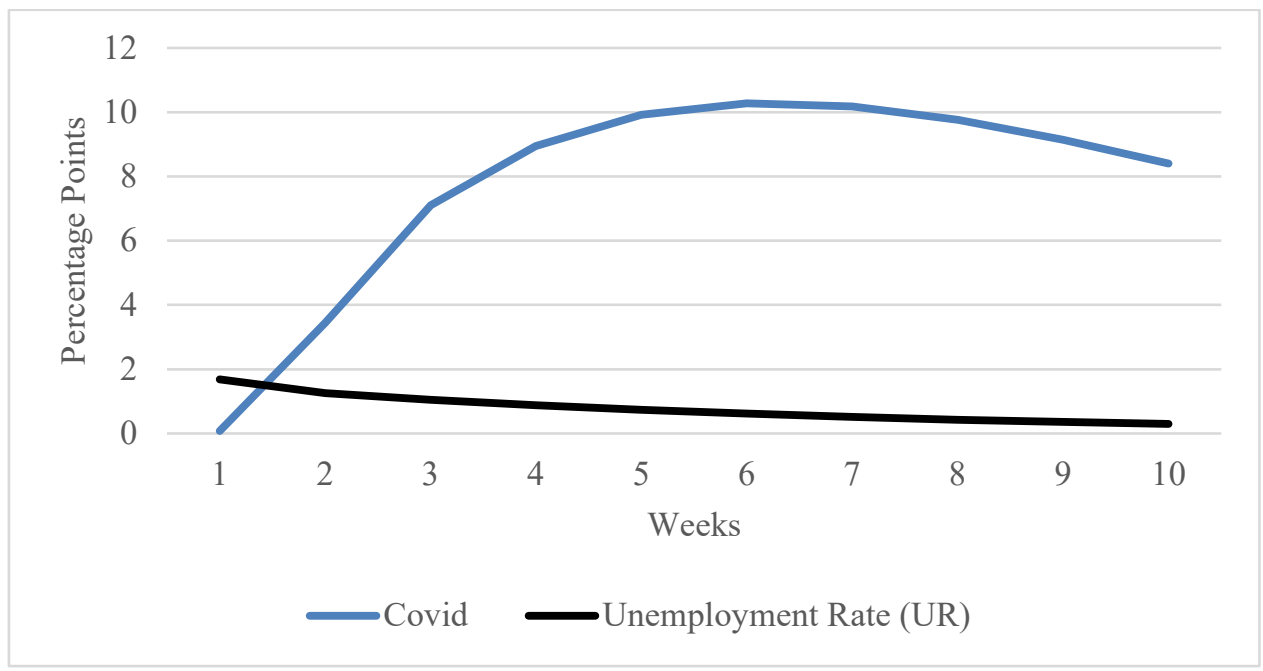

Fig. 3. Impulse response function of unemployment rate.

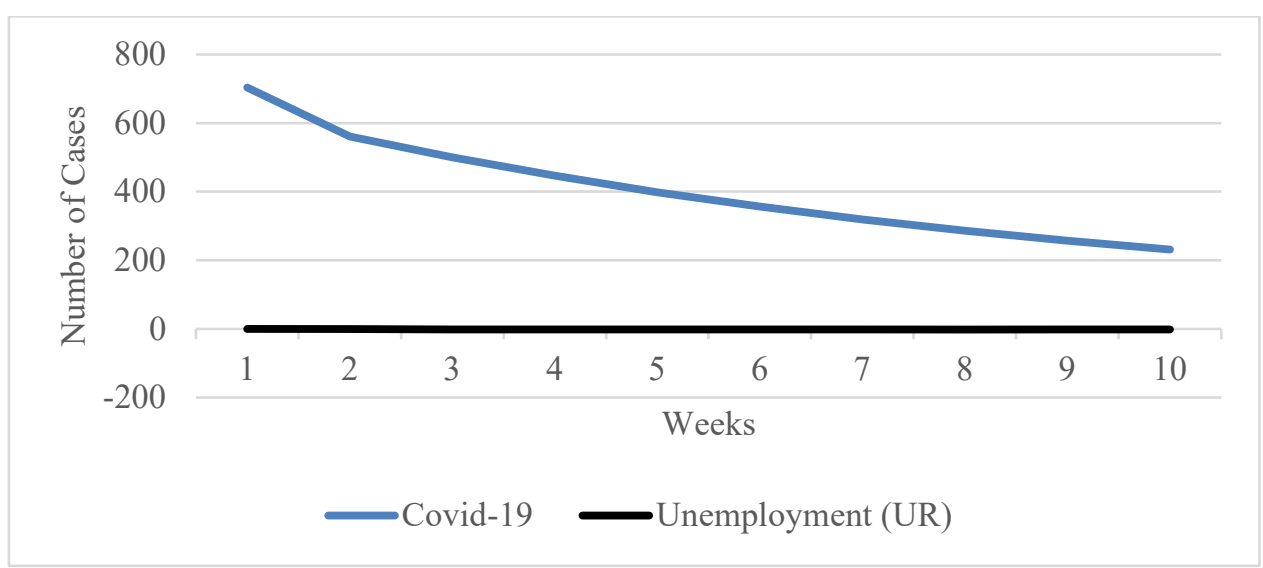

Fig. 4. Impulse response function of Covid-19 contagion level.

The historical variance decomposition (HD) was estimated to assess the role played by each type of perturbation in the fluctuations of UR and Covid-19 last year. These functions are useful for determining the proportion of the unconditional mean of the variables per period that can be attributed to a particular shock. This mean can be taken as the steady-state of the variables. Therefore, the HD shows the impulses responsible for the deviation of the variables from the long-run trend. Figure 5 shows the variation of the Covid-19 contagion level from March 2020 to April 2021, which is explained by innovations in UR. As evident in Fig. 5, these disturbances explain a small portion of the oscillations in the virus infection levels. Thus, this constitutes additional evidence that as measured by the unemployment rate, economic activity does not seem to be responsible for the transmission of the infection. 


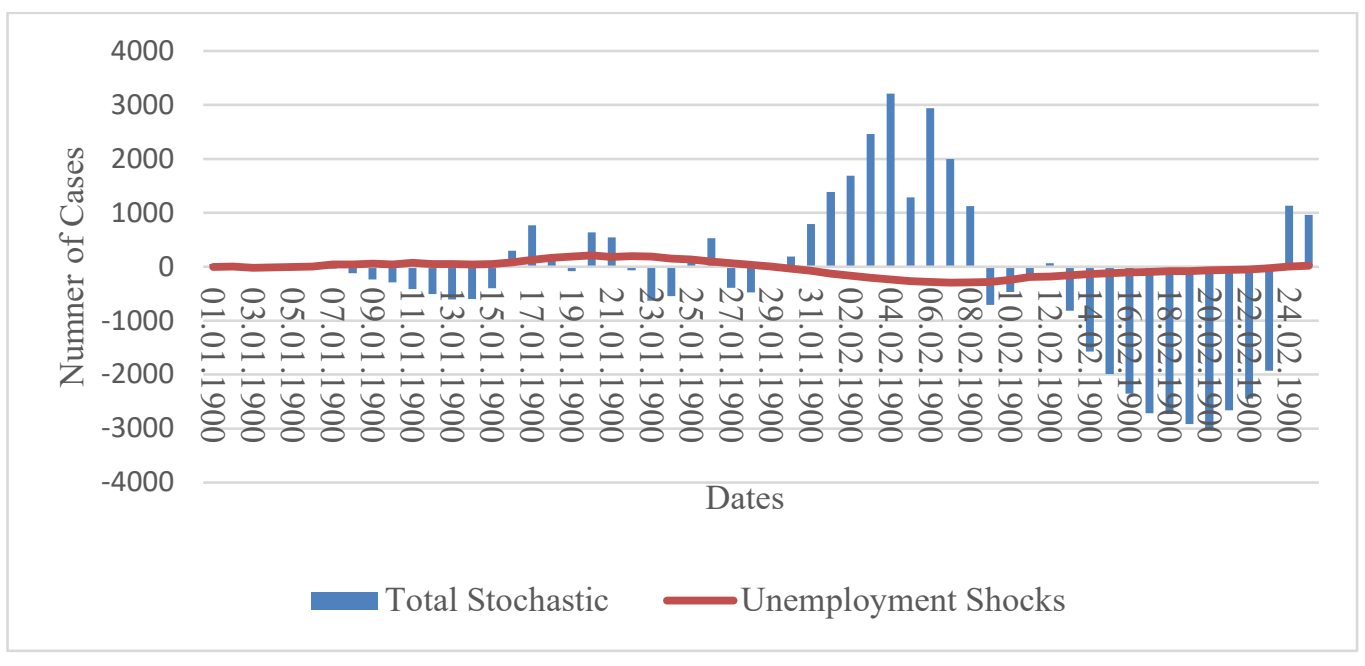

Fig. 5. Historical decomposition of the Covid-19 transmission levels.

On the other hand, the impulses in Covid-19 explain the general trend of UR (see Fig. 6). At the beginning of the pandemic (March 2020), the virus shocks could not reproduce the unemployment rate fluctuations. At that time, most economic activities were shut down as a precautionary measure in anticipation of the effects of the virus on the health of citizens. Thus, the unemployment rate increased without a high virus transmission rate among the country's population at that time. Nevertheless, in Fig. 6, it is possible to observe that after October 2020, the infection disturbances reasonably reproduced the direction of the unemployment rate variations. Furthermore, at the beginning of 2021, most of the variance of the unemployment rate was explained by the Covid-19 perturbations. These results are consistent with those of the Granger causality test and the impulse-response functions discussed above.

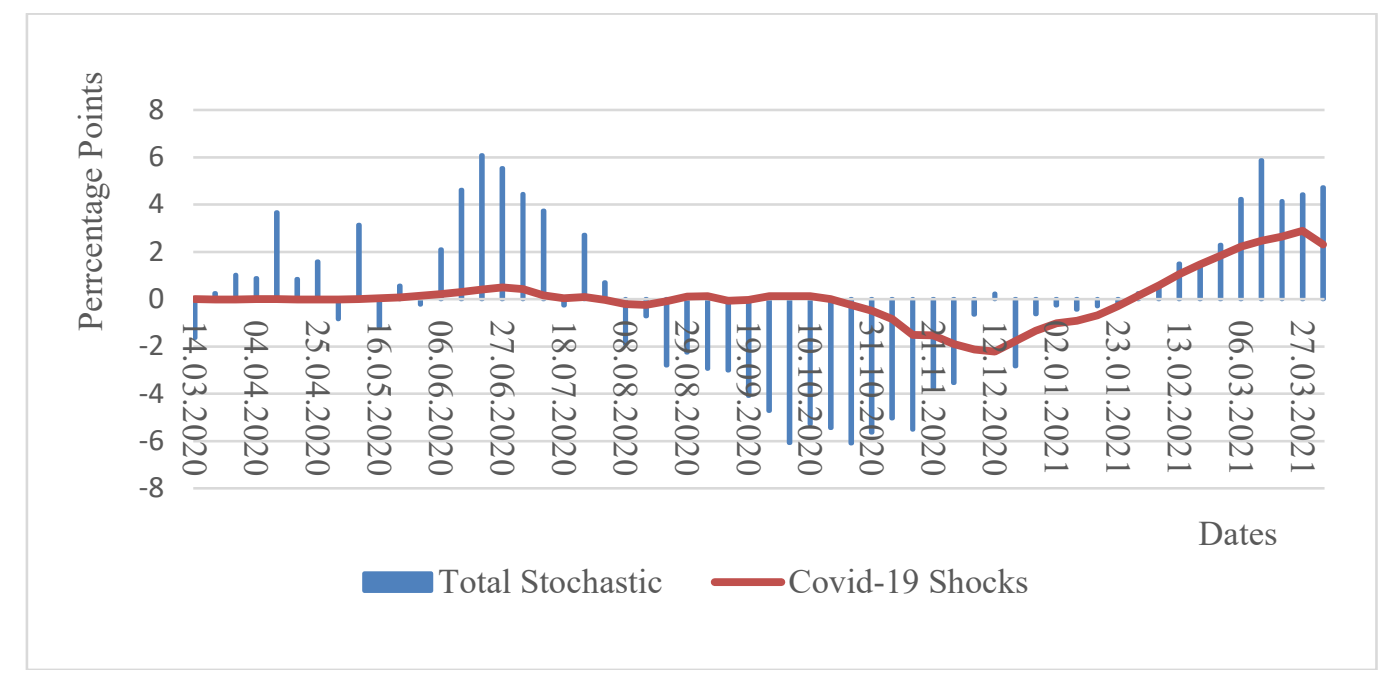

Fig. 6. Historical decomposition of the unemployment rate. 


\section{A MIDAS BAYESIAN VAR}

To deeply analyse the timing relationship between the Covid-19 pandemic and economic activity in Puerto Rico, a Bayesian MIDAS (mixed frequency) VAR model was estimated. This system combines the daily data of the virus infection with the weekly data of the unemployment rate. In this estimation, the same prior and the number of draws and burn-in of the above model were utilised. A sevenorder VAR was specified.

The impulse response (IP) functions were used to evaluate UR response to Covid shocks that occurred on different days of the week. Figure 7 shows the unemployment rate responses to unexpected increases in Covid-19 infection that happened in the first and second days of the week. As it is evident, the unemployment rate has a strong positive response to shocks that occurred at the beginning of the weeks. Figure 8 reports the IP functions for the impulses that originated in the middle of the week. The initial effects of the third and fourth days of Covid perturbations on the unemployment rate are positive. However, the impacts on UR of shocks originated on the third day of the week increase through time, while those originated on the fourth day diminish. In general, these impulses have a more negligible effect on UR than those that take place at the beginning of the week.

Finally, the responses of UR to the Covid-19 perturbances that arise at the end of the week are presented in Fig. 9. The unexpected increases in Covid-19 that occur the last three days of the week negatively impacted the unemployment indicator utilised in this research.

In general, the IP functions from the MIDAS BVAR model line up fairly well with those estimated from a single frequency BVAR model. Nevertheless, the mixed-frequency VAR impulse responses show that the short-term dynamics of the reactions are somewhat distinct depending on the timing of the shock in the week. The shocks at the beginning of the week seem to be most relevant for the unemployment dynamic. This may result from the timing of the decision-making process that made the government authorities regarding the imposition restriction on economic activity. Also, it may be the results of the application schedule for unemployment benefits and their approval that are not necessarily based upon the information of the entire calendar week. Consequently, a shock coming late in the week may not be fully reflected in the government data, so that the timing of the innovations in the week matters for the short-term dynamics of the responses. This may imply a nonlinear relationship between UR and the Covid-19 infection level. This conjecture is explored in the following subsection. 


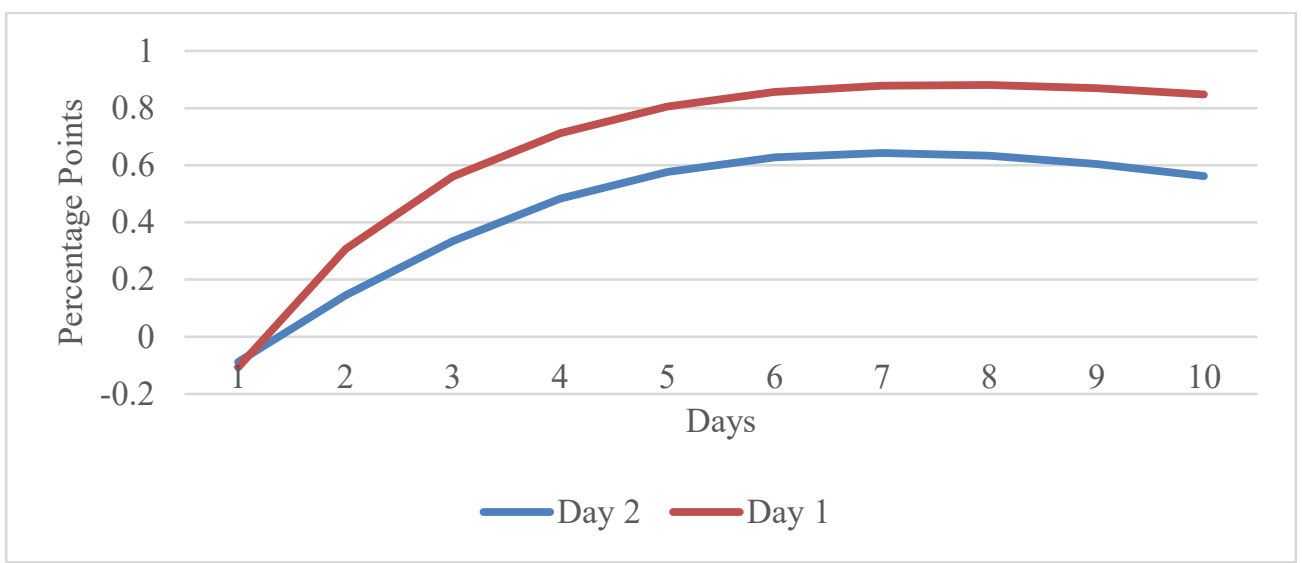

Fig. 7. Responses of unemployment rate to shocks at the beginning of the week.

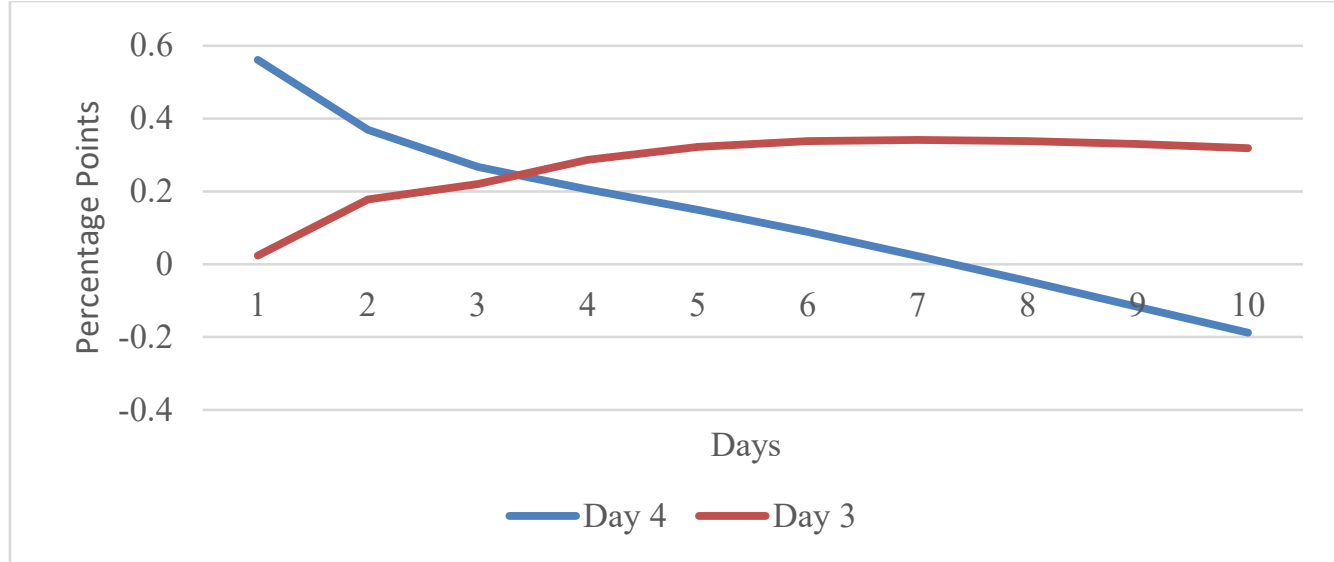

Fig. 8. Responses of unemployment rate to shocks at the middle of the week.

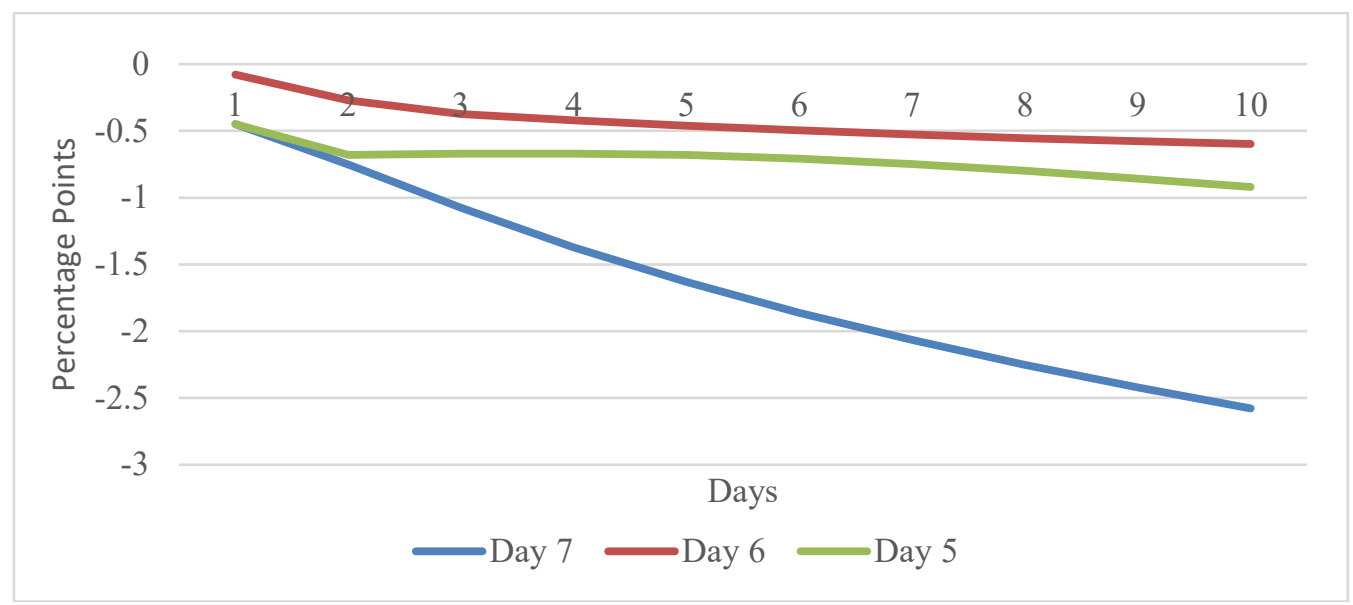

Fig. 9. Responses of unemployment rate to shocks at the end of the week. 


\section{ROBUSTNESS}

A single equation Bayesian model was estimated to determine the sensibility of the findings reported in the previous sections to nonlinear specifications of the models and the prior's selection. For this analysis, a log-linear model of UR as a function of the Covid-19 variable was chosen. The model includes a linear trend variable, a dummy variable for the lockdown period (Dummy 1), and another dummy reflecting a structural change in the model due to other government restrictions (Dummy 2). The Markov Chain Monte Carlo (MCMC) simulation methods based on the Gibbs sampling algorithm were used in the estimation. In this procedure, 50000 samples were generated using two chains, with 10 percent burn-in.

The model parameters were given noninformative priors due to the lack of previous estimation in this subject area. The parameters were modelled by the univariate normal distribution, with a mean $(\mu)$ of 0 and a variance $\left(\sigma^{2}\right)$ of at least 1000 to ensure a very wide distribution so that all plausible parameter values were weighted equally at the outset of the analysis (see Table 2). The variance of the model is assumed to come from an inverse gamma distribution because only positive values are allowed.

Table 2. Parameter Priors

\begin{tabular}{|l|l|}
\hline \multicolumn{1}{|c|}{ Parameter } & \multicolumn{1}{|c|}{ Prior } \\
\hline CONSTANT & $\mathrm{N}\left(\mu=0, \sigma^{2}=1000\right)$ \\
\hline $\log (\mathrm{UR}(-1))$ & $\mathrm{N}\left(\mu=0, \sigma^{2}=1000\right)$ \\
\hline $\log (\mathrm{CC})$ & $\mathrm{N}\left(\mu=0, \sigma^{2}=1000\right)$ \\
\hline$\sigma^{2}$ (residuals) & Inv-Gamma $(0.001,0.001)$ \\
\hline \multicolumn{2}{|c|}{ Source: The author's calculations }
\end{tabular}

The estimation results are presented in Table 3. As seen in Table 3, the mean and median of the parameters estimated for the Covid contagious level variable are positive. This estimation implies that the average elasticity of UR with respect to the Covid virus infectious level is 0.0794 . The $95 \%$ credible interval $^{4}$ for this parameter, [0.0140-0.1448], does not include negative values. Thus, the virus spread tends to increase the unemployment rate.

Table 3. Summary of the Estimation Results

\begin{tabular}{|l|l|l|l|l|l|}
\hline Variable & Mean & St. Dev. & $2.5 \%$ & Median & $97.5 \%$ \\
\hline Log (COVID) & 0.0794 & 0.0333 & 0.0140 & 0.0794 & 0.1448 \\
\hline Dummy 1 & -2.0981 & 0.1641 & -2.4200 & -2.0980 & -1.7737 \\
\hline Dummy 2 & -0.7911 & 0.1482 & -1.0831 & -0.7913 & -0.5013 \\
\hline Linear Trend & -0.0232 & 0.0051 & -0.0333 & -0.0232 & -0.0130 \\
\hline SD (residual) & 0.2678 & 0.0264 & 0.2218 & 0.2658 & 0.3253 \\
\hline \multicolumn{7}{|c|}{ Source. The author's calculations }
\end{tabular}

Source: The author's calculations

\footnotetext{
${ }^{4}$ Interval within which the parameter lies with probability 0.95 .
} 


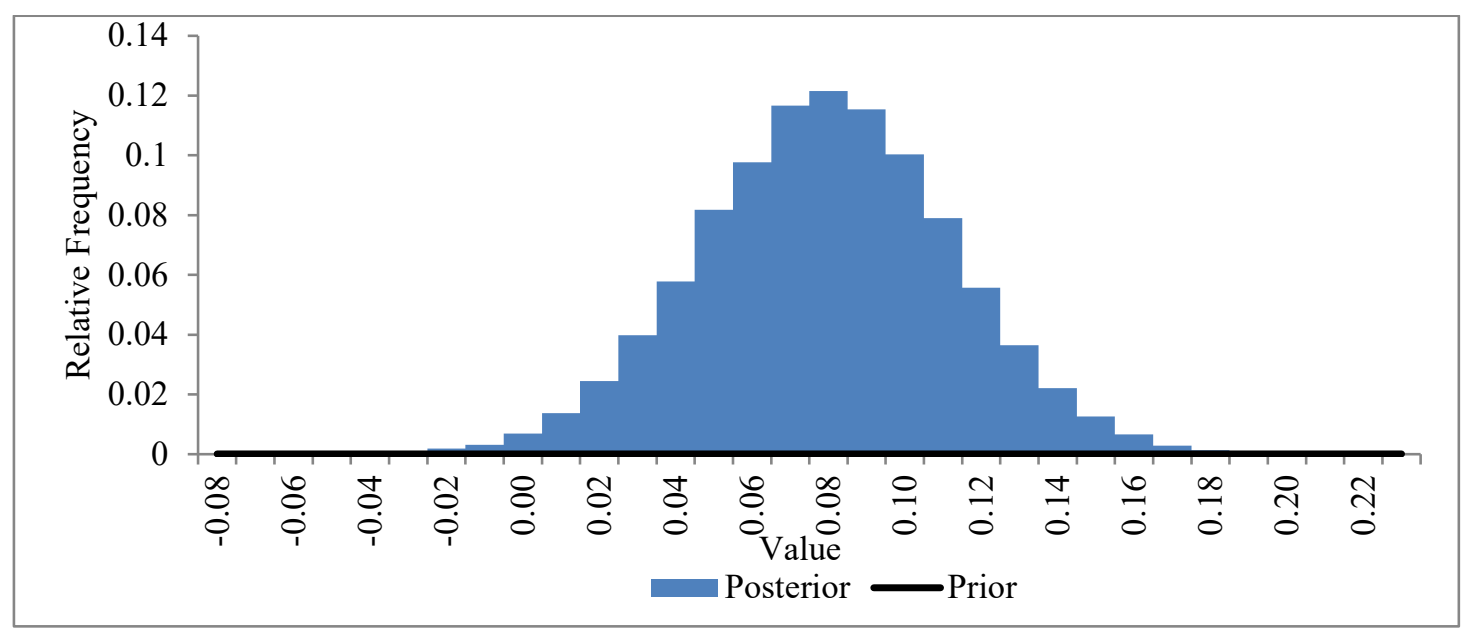

Fig. 10. Posterior distribution of the Covid-19 variable parameter.

Figure 10 presents the posterior distribution of this parameter. Only a small area of this function values lies in the negative range of the real number line. Hence, there is a high probability of the Covid-19 variable having a positive impact on UR. This finding coincides with the estimation results of the BVAR models.

\section{CONCLUSIONS}

The socioeconomic effects of the Covid-19 pandemic have been the object of ample study last year. One restriction that has confronted this line of research is the lack of enough data to examine the issue completely ${ }^{5}$. However, the use of highfrequency data may somewhat mitigate this shortcoming. In this paper, the type of data from Puerto Rico was used to analyse the interaction between economic activity and the virus. The pandemic impact on economic activity comes from at least two sources: infections of the workers, which decreased the level of firms' production, and the containment measures that limited the operations of the businesses. The coronavirus also affects the government's transference payments to individuals.

The analysis implies that the unemployment rate responds moderately to the Covid-19 contagion level and not the other way around. The elasticity of the unemployment rate with respect to the virus, with a high probability of being between 0.0140 and 0.1448 , was estimated. At the beginning of 2021, most of the unemployment rate fluctuations were explained directly by the Covid-19 perturbations. Thus, no evidence was found to the conjecture that economic activity promoted the spread of the virus. Such a finding may be the consequence of the business measures, but it may be the result of government policies.

The principal limitations of this study were related to the data. First, the period under analysis is short, so only the virus very short-run impact may be evaluated. The lack of high-frequency data for most economic indicators impedes examining

\footnotetext{
${ }^{5}$ More extensive cross-section data may be available in the future.
} 
the infection effects on different sectors. Also, the seasonally adjusted data were not available for this study. Finally, the insured unemployment rate used in the analysis is defined as the number of persons receiving unemployment insurance divided by the labour force. The labour force is measured using a sample survey, and there is a high probability of high non-sampling error related to nonresponse during the pandemic.

\section{REFERENCES}

Alfanza, Ma. T. (2021). Telecommuting Intensity in the Context of COVID-19 Pandemic: Job Performance and Work-Life Balance. Economics and Business, 35(1), 107-116. https://doi.org/10.2478/eb-2021-0007

Anderton, R., Botelho, V., Consolo, A., Dias Da Silva, A., Foroni, C., Matthias, M. \& Vivian, L. (2021). The Impact of the COVID-19 Pandemic on the Euro Area Labour Market. Economic Bulletin Articles, European Central Bank, 8. Retrieved from https://www.ecb.europa.eu/pub/economicbulletin/articles/2021/html/ecb.ebart202008_02 bc74 9d90e7.en.html

Baker, S. R., Bloom, N., Davis, S. J., Kost, K. J., Sammon, M. C., \& Viratyosin, T. (2020). The Unprecedented Stock Market Impact of COVID-19. National Bureau of Economic Research Working Paper (26945). https://doi.org/10.3386/w26945

Bauer, A., \& Weber, E. (2020). COVID-19: How Much Unemployment was Caused by the Shutdown in Germany? Applied Economics Letters, 28(12), 1053-1058. https://doi.org/10.1080/13504851.2020.1789544

Christiano, L. J. \& Eichenbaum, M. S. (1986). Temporal Aggregation and Structural Inference in Macroeconomics. National Bureau of Economic Research, Technical Working Papers 0060. Retrieved from https://econpapers.repec.org/scripts/redir.pf?u=http\%3A\%2F\%2Fwww.minneapolisfed.org\%2Frese arch\%2FWP\%2FWP306.pdf; h=repec:fip:fedmwp:306

Coibion, O.,Gorodnichenko, Y., \& Weber, M. (2020). Labor Markets during the COVID-19 Crisis: A Preliminary View. NBER Working Papers 27017, National Bureau of Economic Research. https://doi.org/10.3386/w27017

Doan, T. A., Litterman, R. B. \& Sims, C. A. (1984). Forecasting and Conditional Projections Using Realistic Prior Distributions. Econometric Reviews, 3, 1-100. https://doi.org/10.1080/07474938408800053

Eichenbaum, M.S., Rebelo, S., \& Trabandt, M. (2020). The Macroeconomics of Epidemics. National Bureau of Economic Research Working Paper (26882). Retrieved from http://www.nber.org/papers/w26882.pdf

Falk G., Romero P. D., Carter J. A., Nicchitta I. A. \& Nyhof, E. C. (2021). Unemployment Rates During the COVID-19 Pandemic. Congressional Research Service R46554. Retrieved from https://crsreports.congress.gov

Gormsen N. J \& Koijen, R. S. J. (2020). Coronavirus: Impact on Stock Prices and Growth Expectations. NBER Working Papers 27387. https://doi.org/10.3386/w27387

Haroon, O., \& Rizvi, S. A. R. (2020). COVID-19: Media Coverage and Financial Markets Behavior: A Sectoral Inquiry. Journal of Behavioral and Experimental Finance, 27, 100343. https://doi.org/10.1016/j.jbef.2020.100343

ILO \& OECD (2020). The Impact of the COVID-19 Pandemic on Jobs and Incomes in G20 Economies. ILO-OECD Paper Prepared at the Request of G20 Leaders, Saudi Arabia's G20 Presidency, G20 Saudi Arabia, 1-46. Retrieved from https:/www.ilo.org/global/about-theilo/how-the-ilo-works/multilateral-system/g20/reports/WCMS_756331/lang--en/index.htm

Jorda, O., Singh, S. R., \& Taylor, A. M. (2020). Longer-Run Economic Consequences of Pandemics. National Bureau of Economic Research Working Paper (26934). https://doi.org/10.3386/w26934. 
Lewis, D. J., Mertens, K., Stock, H. H. \& Trivedi, M. (2020). High Frequency Data and a Weekly Economic Index During the Pandemic. Federal Reserve Bank of New York Staff Reports, no. 954. Retrieved from https://www.newyorkfed.org/research/staff_reports/sr954

Litterman, R. (1980). A Bayesian Procedure for Forecasting with Vector Autoregression. Working paper, Massachusetts Institute of Technology, Department of Economics.

Onyele, K.O., \& Nwadike, E.C. (2020). Dynamics of Stock Returns amidst COVID-19 Lockdown: A Descriptive Analysis of Global Stock Markets. International Journal of Scientific Research in Multidisciplinary Studies, 6(12), 18-26.

Puerto Rico Department of Health, database. COVID-19 en Cifras en Puerto Rico (COVID-19 in Figures in Puerto Rico). https://www.salud.gov.pr/estadisticas_v2\#casos

Shobande, O., \& Ogbeifun, L. (2020). A Spatial Econometric Analysis on the Impact of COVID-19 on Mortality Outcome. Economics and Business, 34(1), 179-200. https://doi.org/10.2478/eb2020-0013

Topcu, M., \& Gulal, O. S. (2020). The impact of COVID-19 on Emerging Stock Markets. Finance Research Letters, 36, 101691. http://dx.doi.org/10.1016/j.frl.2020

U.S. Bureau of Labour Statistics (n.a.). U.S. Employment and Training Administration, U.S. Department of Labor, Insured Unemployment Rate in Puerto Rico [PRIINSUREDUR], retrieved April,10 2021, from: FRED, Federal Reserve Bank of St. Louis. Retrieved from https://fred.stlouisfed.org/series/PRIINSUREDUR

Yu, Z., Xiao, Y., Li, Y. (2020). The response of the Labor Force Participation Rate to an Epidemic: Evidence from a Cross-Country Analysis. Emerging Markets Finance and Trade, 56(10), 23902407. https://doi.org/10.1080/1540496X.2020.1787149

\section{AUTHOR'S SHORT BIOGRAPHY}

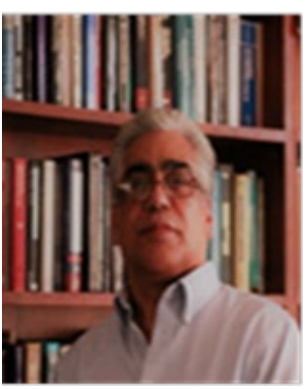

Wilfredo Toledo received a $\mathrm{PhD}$ degree in Economics, with emphasis on Econometrics, Applied Statistics, and Monetary Theory and Policy, from Florida State University (USA) in 1990. Dr. Toledo also holds accreditation as a Professional Statistician (Pstat ${ }^{\circledR}$ ) from the American Statistical Association. He taught for 30 years at the University of Puerto Rico. Actually, he holds a position of Researcher/Consultant at Econometrics and State Research in Puerto Rico. Dr. Wilfredo Toledo has published over 40 professional articles in international journals and has acted as a reviewer for several journals from Latin America, the United States, Asia, and Europe. E-mail: mailto:wilfredotoledo@aol.com

ORCID ID: https://orcid.org/0000-0003-3747-2557 